\title{
Shifting to digital: a policy perspective on 'Student perceptions of privacy principles for learning analytics' (Ifenthaler \& Schumacher 2016)
}

\author{
Linda Corrin ${ }^{1}$ (D) \\ Accepted: 21 November 2020 / Published online: 8 January 2021 \\ (c) Association for Educational Communications and Technology 2021
}

\begin{abstract}
This article considers Ifenthaler and Schumacher's (in Educ Technol Res Dev 64(5):923$938,2016)$ paper entitled "Student perceptions of privacy principles for learning analytics" from a policy perspective. The increasing shift to digital occurring across the education landscape has resulted in greater access to data that can be used to enhance the student learning experience. However, it is essential that appropriate policy be in place to ensure the ethical use of such data, and equally important that the student voice be included in the development of such policy. Ifenthaler and Schumacher's study investigates students' preferences for the types of learning analytics systems they would like to be able to access and willingness to share their data for use in these systems. They find that students would like access to learning analytics systems that provide a broad range of information that can promote metacognitive awareness and provide personalised feedback, but are not entirely comfortable with sharing the full range of data necessary to inform such systems. These findings are important in acknowledging the difficulties in building a shared understanding and vocabulary when speaking to students about the possibilities and ethical implications of learning analytics. Consequently, further consideration is needed to build students' understanding of the purposes and benefits of sharing data as well as awareness of the range of policies that inform a consultative process around systems implementation to ensure transparency and accountability so that learning analytics can play an effective, but safe, role in our increasingly digital education environments.
\end{abstract}

Keywords Learning analytics $\cdot$ Privacy $\cdot$ Data $\cdot$ Policy

The 'shift to digital' that has been increasingly impacting the higher education landscape, and has been accelerated recently due to the global COVID-19 pandemic, brings with it many opportunities for the utilisation of learning analytics to enhance student learning. The increase in the use of digital technology to support learning and teaching means an increase in the generation of data that can be analysed to provide insights into students'

Linda Corrin

lcorrin@swin.edu.au

1 Swinburne University of Technology, Melbourne, Australia 
behaviour and academic achievement. However, with this increased flow of data and continually evolving range of analytics tools and techniques, it is necessary to stop and consider whether the data is being used in ways that are ethical and do not create risk or harm to students. From a policy perspective, appropriate policies and procedures need to be put in place and enforced to ensure the security, privacy, and ethical use of student data. In developing such policies, it is vital to consider students' perspectives on what data they are willing to share, and for what purposes, to align their needs and concerns with the processes and safeguards set in place (Prinsloo and Slade 2013).

Insight into students' views about the use of their data for learning analytics is the focus of Ifenthaler and Schumacher's (2016) paper entitled "Student perceptions of privacy principles for learning analytics". In this 2015 paper, the authors report on an exploratory study conducted with 330 students at a German university. The study was designed to investigate students' preferences for the types of learning analytics systems they would like to be able to access and how willing they are to share different data relating to themselves for use in these systems. The students were presented with three examples of systems that represented a range of different design principles from external support and internal regulation (System 1), to reflective thinking and extrinsic motivation (System 2), through to prompting, metacognitive awareness, and personalised feedback (System 3).

It was found that the majority of students showed a preference for the system that offered the broadest range of information about learning and support (System 3) However, while most students were willing to share enrolment data and results from motivation and learning strategy tests, they were less keen to share behavioural data, and even less comfortable sharing personal data. This finding presents challenges for learning analytics system design, as to be able to deliver the range of information presented in their preferred system it is necessary to have access to the data that students were less willing to share. The main recommendation that Ifenthaler and Schumacher draw from these findings is the need for students and other key stakeholders (e.g. teachers, administrators, etc.) to be involved in discussions about the implementation of learning analytics systems, to ensure transparency, and to balance potential benefits of the system with students' interests.

From a policy perspective, this study was designed to respond to calls in the learning analytics community about the need to incorporate students' perspectives in the development of policies, processes, and tools for learning analytics (Prinsloo and Slade 2013; Pardo and Siemens 2014). The study provided a model for how students could be introduced to the idea of learning analytics through the use of exemplar systems to elucidate willingness to share their data for these purposes. Subsequent studies have adopted a similar approach including Roberts et al. (2016), Arnold and Sclater (2017), Khan (2017), and Bennett (2018). However, as Ifenthaler and Schumacher acknowledge in their paper, this approach can result in lower external validity, as students may only think about data within the context of the examples given. Brooker et al. (2017) tried to address this limitation by gathering students' perspectives without reference to definitions or exemplars of learning analytics, which proved to be a broader, but more difficult conversation. Both these approaches highlight the challenge of building a shared understanding and vocabulary when speaking to students about the possibilities and ethical implications of learning analytics.

As a baseline, it is imperative that institutions have key policies in place regarding student privacy and data governance, aligned to local legislation, to protect students' rights and to give them agency in decisions related to the use of their data. In addition, policy and/or processes around future implementation of systems that rely on student data to provide analytics should require inclusion of the student voice. This could be via consultation 
with a student representative group, or through calls for feedback from the student body. In doing this, it is important to communicate the potential benefits of the system to students so they can make an informed decision about the value of providing their data. One risk of this approach is that small dissent in the student body could prevent the implementation of educationally valuable systems. Possible resolutions for this risk could be, where possible, the provision of systems that are available to all, but allow students to opt in or out, or else the creation of further policies to guide the appropriate access to and use of these systems and related processes to ensure adherence to these policy conditions.

The shift to digital, while providing many opportunities for learning analytics, also presents challenges in ensuring data are used ethically. Ifenthaler and Schumacher's work provides an initial consideration of how to include the student voice when developing policies for learning analytics implementation. It is necessary that this exploration also expand beyond the notion of privacy to incorporate a broader range of ethical issues (Corrin et al. 2019) and consider how the perspectives of multiple stakeholders (including students) can be amalgamated and addressed in policy development and learning analytics design (Chen and Zhu 2019). Subsequently, there is also work needed to build awareness of the range of policies that inform and emerge from this consultative process to ensure transparency and accountability so that learning analytics can play an effective, but safe, role in our increasingly digital education environments.

\section{Compliance with ethical standards}

Conflict of interest No conflict of interest exists.

Research involving human participants and/or animals As this work is a commentary on previously published work there were no human/animal participants.

Informed consent As this work is a commentary on previously published work there were no human/animal participants to consent.

\section{References}

Arnold, K. E., \& Sclater, N. (2017). Student perceptions of their privacy in leaning analytics applications. In X. Ochoa, I. Molenaar, \& S. Dawson (Eds.), Proceedings of the 7th International Conference on Learning Analytics and Knowledge (pp. 66-69). New York: ACM.

Bennett, L. (2018). Students' responses to learning analytics dashboards: Research report. Huddersfield, UK: University of Huddersfield.

Brooker, A., Corrin, L., Fisher, J., \& Mirriahi, N. (2017). Defining "data" in conversations with students about the ethical use of learning analytics. In H. Partridge, K. Davis, \& J. Thomas (Eds.), Proceedings of ASCILITE 2017: 34th International Conference on Innovation, Practice and Research in the Use of Educational Technologies in Tertiary Education (pp. 27-31). Toowoomba, Australia: ASCILITE.

Chen, B., \& Zhu, H. (2019). Towards value-sensitive learning analytics design. Proceedings of the 9th International Conference on Learning Analytics \& Knowledge (pp. 343-352). New York: ACM.

Corrin, L., Kennedy, G., French, S., Buckingham, S. S., Kitto, K., Pardo, A., et al. (2019). The ethics of learning analytics in Australian higher education. A discussion paper. Melbourne, Australia. MCSHE.

Ifenthaler, D., \& Schumacher, C. (2016). Student perceptions of privacy principles for learning analytics. Educational Technology Research and Development, 64(5), 923-938. https://doi.org/10.1007/s1142 3-016-9477-y.

Khan, O. (2017). Learners' and teachers' perceptions of learning analytics (LA): A case study of Southampton Solent University (SSU). In D. Sampson, J. M. Spector, D. Ifenthaler, \& P. Isaias (Eds.), 
Proceedings of the 14th International Conference on Cognition and Exploratory Learning in Digital Age (CELDA) (pp. 267-272). Setúbal, Portugal: IADIS Press.

Pardo, A., \& Siemens, G. (2014). Ethical and privacy principles for learning analytics. British Journal of Educational Technology, 45(3), 438-450. https://doi.org/10.1111/bjet.12152.

Roberts, L. D., Howell, J. A., Seaman, K., \& Gibson, D. C. (2016). Student attitudes toward learning analytics in higher education: 'The Fitbit Version of the Learning World.' Frontiers in Psychology, 9(1959), 1-11. https://doi.org/10.3389/fpsyg.2016.01959.

Slade, S., \& Prinsloo, P. (2013). Learning analytics: Ethical issues and dilemmas. American Behavioral Scientist, 57(10), 1510-1529. https://doi.org/10.1177/0002764213479366.

Publisher's Note Springer Nature remains neutral with regard to jurisdictional claims in published maps and institutional affiliations.

Linda Corrin is Director, Learning Transformations Unit and Associate Professor, Learning Analytics at Swinburne University of Technology in Melbourne, Australia. Her research interests include learning analytics, educational technology, feedback, and learning design. She is currently working on several research projects exploring how learning analytics can be used to provide meaningful and timely feedback to academics and students. 